\title{
Dictamen acerca de la situación jurídica en que se encuentran los terrenos conocidos como las «Vecindades» del pueblo de Pontejos, Ayuntamiento de Marina de Cudeyo (Cantabria)
}

\author{
Luis Rojo Ajuria \\ Catedrático de Derecho Civil \\ Juan Manuel Alegre Ávila \\ Profesor Titular Derecho Administrativo
}

Sumario: I. ANTECEDENTES. II. CONSULTA FORMULADA POR LA JUNTA VECINAL DE PONTEJOS. III. APROVECHAMIENTOS COMUNALES Y POTESTADES DE INTERVENCION DE LA JUNTA VECINAL DE PONTEJOS EN RELACIÓN CON LOS TERRENOS DE LAS «VECINDADES». IV. LA ENFITEUSIS COMO POSIBLE ORIGEN DE LA TITULARIDAD VECINAL DE LOS TERRENOS. V. LA DONACIÓN CON PROHIBICIÓN DE DISPONER COMO ORIGEN DE LA SITUACIÓN ACTUAL. VI. LA JUNTA VECINAL O PEDANÍA DE PONTEJOS COMO TITULAR DOMINICAL O PROPIETARIA DE LOS TERRENOS DE LAS “VECINDADES». VII. LA CALIFICACIÓN JURIDICA DE LOS TERRENOS DE LAS "VECINDADES» COMO BIENES COMUNALES: PROPIEDAD PÚBLICA Y APROVECHAMIENTO COMUNAL. VIII. RÉGIMEN JURIDICO DE LOS TERRENOS DE LAS "VECINDADES» Y POSIBILIDADES DE TRANSFORMACIÓN EVOLUTIVA DE LOS MISMOS. IX. EL PESO DE LA HISTORIA COMO CONDICIONANTE DE LAS POSIBILIDADES DE TRANSFORMACIÓN EVOLUTIVA DE LOS TERRENOS DE LAS "VECINDADES». X. PROPUESTAS ACERCA DE LAS POSIBILIDADES DE TRANSFORMACIÓN EVOLUTIVA DE LOS TERRENOS DE LAS «VECINDADES». CONCLUSIONES.

\section{ANTECEDENTES}

La consulta sometida a dictamen de los letrados informantes requiere una sucinta descripción de los antecedentes que están en la base de aquélla. Estos antecedentes son los siguientes: 
- En 25 de noviembre de 1991 el Alcalde del Ayuntamiento de Marina de Cudeyo (CANTABRIA) se dirige al Excmo. y Magfco. Sr. Rector de la Universidad para que, en el marco del convenio suscrito entre la Universidad y el Ayuntamiento, se proceda por la Facultad de Derecho a emitir informe jurídico sobre los diferentes extremos planteados por la Junta Vecinal de Pontejos, Ayuntamiento de Marina de Cudeyo.

- Los referidos extremos son los contenidos en el escrito de la Junta Vecinal de PONTEJOS de 11 de noviembre de 1991, escrito dirigido al Sr. Alcalde Presidente del Ayuntamiento de Marina de Cudeyo. En concreto, en el mismo se interesaba una respuesta en Derecho acerca de la situación jurídica en que se encuentran unos terrenos conocidos con el nombre de "VECINDADES", sitos en el pueblo de Pontejos, y que vienen siendo disfrutados, en virtud de las adjudicaciones de los oportunos lotes, por los vecinos del citado pueblo de Pontejos.

- Los citados terrenos, cuya primera referencia documental data de 1753 (escrito de la Junta Vecinal de Pontejos de 11 de noviembre de 1991), son designados en los documentos aportados por la Junta Vecinal con diversas denominaciones (tierras del Concejo, Hacienda del Concejo, Vecindad, Hacienda del Pueblo, Terrenos de la Obra Pía, Vecindades). Asimismo, y con independencia de su discontinua localización en el término municipal de Marina de Cudeyo, e, incluso, la dificultad de su identificación (registral y, probablemente, física), podemos dar por bueno el origen de la presente situación, cifrado, según escrito dirigido en 11 de noviembre de 1959 por el Presidente de la Junta Vecinal de Pontejos a la Abogacía del Estado en Santander, en la cesión efectuada en 1845, en concepto de enfiteusis, por el Sr. Marqués de Valdecarrana a cincuenta y dos vecinos del pueblo de Pontejos.

- Según testimonio del Alcalde Pedáneo de Pontejos (escrito de 11 de noviembre de 1991), la Junta Vecinal, en relación con los terrenos de las "Vecindades», ha venido llevando a cabo (sin solución de continuidad, al menos desde el año 1931, de acuerdo con la documentación aportada - diversos acuerdos de la Junta Vecinal respecto de los indicados terrenos-) distintas actuaciones sobre adjudicación de lotes en caso de sucesión o vacantes (extremo que conlleva el reconocimiento de la condición de vecino), recaudación de los correspondientes tributos (uno de cuyos aspectos es el reflejado en el antes mencionado escrito del Presidente de la Junta Vecinal de Pontejos de 11 de noviembre de 1959, al cual nos referiremos posteriormente) y 
DICTAMEN ACERCA DE LA STIUACIÓN JURIDICA EN QUE SE ENCUENTRAN LOS TERRENOS DE LAS "VECINDADES"

establecimiento de las normas de uso y administración de los terrenos en cuestión, expresivos todos ellos del ejercicio de un conjunto de potestades cuya traducción jurídica es justamente el objeto de esta consulta.

\section{CONSULTA FORMULADA POR LA JUNTA VECINAL DE PONTEJOS}

Sobre la base de estos antecedentes, la Junta Vecinal de Pontejos formula consulta acerca de «la naturaleza jurídica de estos bienes, régimen jurídico aplicable y facultades de la Junta Vecinal sobre ellos» (escrito de 11 de noviembre de 1991). A su vez, esta consulta es desglosada (escrito de 10 de marzo de 1992, dirigido a la Facultad de Derecho de la Universidad de Cantabria) en la formulación de siete cuestiones, que literalmente transcritas son las siguientes:

1. Si se puede considerar una donación a la Junta Vecinal o a los vecinos, o si en todo caso la Junta tiene el dominio sobre los terrenos por algún otro título.

2. Si puede tratarse de una donación condicionada.

3. Posibilidad de la Junta de vender los lotes a los actuales poseedores y en qué condiciones.

4. Posibilidades de enajenación a terceros no poseedores.

5. Posibilidades de poner fin al derecho de los poseedores en los suelos calificados como urbanos.

6. Posibilidades de modificar la configuración de los lotes con carácter previo a la posible enajenación.

7. Posibilidad de retirar los derechos sobre los lotes a personas que han trasladado su domicilio del pueblo hace un gran número de años (entre 10 y 20 , aproximadamente).

En síntesis, las diferentes cuestiones suscitadas al hilo de la presente consulta, se resumen en el planteamiento y resolución de los tres siguientes extremos, a saber:

1. Titularidad (y, en su caso, titularidades) de los terrenos comprendidos en las "Vecindades».

2. Naturaleza jurídica de los indicados terrenos.

3. Régimen jurídico a que se sujetan estos terrenos y, en consecuencia, posibilidades de actuación respecto de los mismos.

Procedamos, pues, a dar respuesta a los anteriores aspectos. 


\section{APROVECHAMIENTOS COMUNALES Y POTESTADES DE INTERVENCIÓN DE LA JUNTA VECINAL DE PONTEJOS EN RELACIÓN CON LOS TERRENOS DE LAS «VECINDADES»}

Resulta incontestable (al menos, desde 1931, fecha a que se remonta la actuación documentada más antigua de la Junta Vecinal de Pontejos en relación con los terrenos de las "Vecindades», según antes se dijo) que los terrenos a que se contrae esta consulta han venido siendo aprovechados por los vecinos de Pontejos, de acuerdo con los lotes de que han sido en cada momento adjudicatarios, y de conformidad con las normas sobre uso fijadas por la Junta Vecinal de Pontejos. Normas sobre uso de que no hay constancia en la documentación aportada, si bien es de suponer que las mismas han sido establecidas ateniéndose al peculiar modo de funcionamiento de esta concreta modalidad de organización administrativa que es la Junta Vecinal (el Concejo, abierto o con la intermediación representativa de la Junta). Por otro lado, es igualmente de presumir que los específicos usos o aprovechamientos de los terrenos en cuestión se han acomodado históricamente a las particulares exigencias demandadas por la realidad socioeconómica.

La cuestión, por tanto, que ha de ser precisada estriba en determinar el título jurídico en virtud del cual se han cumplido los diversos y sucesivos usos y aprovechamientos por parte de los vecinos de Pontejos. Base jurídica que, en hipótesis, puede estar constituida tanto por una titularidad dominical (un verdadero derecho de propiedad en sentido estricto) como por otra cualquiera titularidad jurídica legitimadora de los referidos usos y aprovechamientos. Asimismo, y como derivación de la anterior, a la cual sin embargo se halla íntimamente ligada, ha de concretarse el titular del derecho (de propiedad o cualquier otro que sea bastante) que permita dar explicación suficiente de la obtención por los vecinos de las utilidades a que se ciñen los anteriores usos y aprovechamientos. $Y$ en esta tesitura no caben sino dos posibilidades: o los titulares de este. derecho (sin prejuzgar ahora su naturaleza y calificación jurídicas) son los propios vecinos, o, por el contrario, aquél es predicable de la organización grupal que aglutina a los vecinos, es decir, la Junta Vecinal de Pontejos, que con este carácter aparece en los documentos suministrados desde, al menos, 1931.

Seguidamente, abordaremos el examen de la situación, desde la perspectiva de su atribución dominical o propietaria, de los terrenos de las «Vecindades». 
DICTAMEN ACERCA DE LA SITUACIÓN JURIDICA EN QUE SE ENCUENTRAN LOS TERRENOS DE LAS "VECINDADES

\section{LA ENFITEUSIS COMO POSIBLE ORIGEN DE LA TITULARIDAD VECINAL DE LOS TERRENOS}

\section{Planteamiento del problema}

La enfiteusis nació en Derecho romano como la concesión de tierra agrícola por tiempo indefinido, a cambio de una renta que el cultivador tenía que entregar al propietario. El concedente de la tierra seguía considerándose propietario de la misma, a pesar de la amplitud del gravamen y de su duración indefinida, que son elementos que permitieron más tarde considerar que en la enfiteusis hay una división del dominio, y después, que el verdadero dueño es el llevador de la tierra o enfiteuta.

La concepción moderna es que el enfiteuta es el dueño efectivo de la finca y que el censualista tiene sobre ella un derecho real de complejo contenido. Tal concepción queda reflejada en el artículo 1605 del Código Civil: Es enfitéutico el censo cuando una persona cede a otra el dominio útil de una finca, reservándose el directo y el derecho a percibir del enfiteuta una pensión anual en reconocimiento de este mismo dominio.

En lo que interesa al caso planteado es preciso destacar el último inciso del artículo 1605: el derecho a percibir del enfiteuta una pensión anual en reconocimiento de este mismo dominio. Nótese que la pensión tiene de manera predominante la función de un reconocimiento reiterado del derecho del dueño directo, por lo que tal pensión puede ser meramente simbólica o de valor económico prácticamente nulo. Y es que dado que el enfiteuta tiene el llamado dominio útil, mientras que el dominio directo se ha convertido en realidad en una carga real, se entiende fácilmente que el Código Civil se preocupe especialmente del reconocimiento de su derecho, para evitar que mediante la prescripción adquisitiva o usucapión.el enfiteuta adquiera el pleno dominio sobre la finca.

Es por esta misma razón por la que el Código Civil dedica especificamente otro artículo, el 1647, a tratar esta cuestión: Cada veintinueve años podrá el dueño directo exigir el reconocimiento de su derecho por el que se encuentre en posesión de la finca enfitéutica. La cifra de veintinueve años se explica fácilmente en relación con el juego de la prescripción extintiva y de la prescripción adquisitiva: Las acciones reales sobre bienes inmuebles prescriben a los treinta años (artículo 1963); se prescriben también el dominio y los demás derechos reales sobre los bienes inmuebles por su posesión no interrumpida durante treinta años, sin necesidad de título ni de buena fe (artículo 1959). Es decir, para evitar la cifra fatídica de los treinta años, que supone la prescripción de su dere- 
cho y la adquisición plena del dominio por el enfiteuta, el artículo 1647 establece un específico derecho de reconocimiento a favor del dueño directo, estableciendo además que los gastos de reconocimiento serán de cuenta del enfiteuta.

\section{Consecuencias respecto del presente caso}

Es muy posible que el origen de la actual situación tuviese su origen en la creación de una enfiteusis, y así sucedió históricamente en la creación de muchas comunidades vecinales. Pero lo que sí es absolutamente cierto es que tal origen carece actualmente de consecuencias jurídicas. $\mathrm{Si}$ desde hace ya bastante más de treinta años no ha habido ningún reconocimiento del derecho del dueño directo parece claro que con el paso del tiempo el dominio útil de la comunidad de vecinos se convirtió en un dominio pleno.

Nada obsta para ello el que en ciertos documentos se haya utilizado algún tipo de denominaciones con referencia a la enfiteusis. El reconocimiento del derecho del dueño directo se ha de referir a un concreto titular de tal derecho. Es claro que desaparecido el derecho del que en su momento fue dueño directo, y de sus causahabientes, carece de sentido hablar de enfiteusis, salvo como una mera referencia histórica, o como una forma descriptiva de referirse a los terrenos.

En conclusión, la aplicación de los artículos 1647, 1959 y 1963 del Código Civil permite mantener que, en la hipótesis del origen de la situación actual en una enfiteusis, desde el momento en que transcurrieron más de treinta años sin que existiese un reconocimiento del derecho del dueño directo, la comunidad de vecinos pasó a ser titular de un dominio pleno sobre las fincas.

Por lo tanto, las facultades de disfrute y disposición sobre tales fincas habrán de establecerse de acuerdo con la situación actual, y la correspondiente regulación legal aplicable, sin que se vea afectada por sus orígenes.

\section{LA DONACIÓN CON PROHIBICIÓN DE DISPONER COMO ORIGEN DE LA SITUACIÓN ACTUAL}

\section{Planteamiento del problema}

En realidad, la hipótesis planteada sugiere un falso problema. Uno de los principios que rige el derecho de propiedad es que la propiedad 
DICTAMEN ACERCA DE LA SITUACION JURIDICA EN OUE SE ENCUENTRAN LOS TERRENOS DE LAS 'VECINDADES"

se presume libre de cargas. Quien alega la existencia de una carga sobre un derecho de propiedad es quien ha de probar su existencia. Carece de sentido que un propietario especule acerca de si su propiedad está sometida a alguna carga, careciendo tal especulación de una base real como sucede en el presente caso.

Admitiendo la hipótesis a efectos puramente especulativos, y obviando la cuestión de toda la legislación desamortizadora del siglo XIX, se puede afirmar que en nuestro Derecho se admite la posible existencia de prohibiciones de disponer con efectos reales en una donación (así, los artículos 26 y 27 de la Ley Hipotecaria). Ahora bien, se entiende que si la vinculación de bienes hereditarios está sometida a límites temporales, para evitar la amortización de la propiedad, con mayor razón deben tenerlos las prohibiciones de enajenar impuestas por actos inter vivos.

Por tanto, se consideran aplicables los artículos $785-2^{\circ}$ y 781 del Código Civil, que establecen que serán válidas y surtirán efecto siempre que no pasen del segundo grado, o que se hagan en favor de personas que vivan al tiempo del fallecimiento del testador. Dado que en el presente caso ha transcurrido con creces el límite de dos generaciones establecido en el Código Civil, incluso admitiendo tal hipótesis a efectos puramente especulativos, e incluso prescindiendo de la incidencia de toda la legislación desamortizadora y administrativa, se podría afirmar que la prohibición de disponer habría superado los límites temporales dentro de los cuales se le reconocen efectos.

Por último, se exige doctrinal y jurisprudencialmente que la prohibición de disponer esté basada en un interés justo y legítimo, por lo que se ha sostenido que también cesa la prohibición cuando sólo disponiendo (con las garantías precisas) se consigue la finalidad pretendida por el que impuso aquélla. En el presente caso, la prohibición de disponer sólo se podría entender en beneficio de los propios vecinos, por lo que si, dado el cambio de circunstancias, el interés de éstos se viese mejor satisfecho con la disposición, la prohibición perdería la base del interés justo y legítimo.

\section{Consecuencias respecto del presente caso}

Si se parte de la base de la propiedad de la comunidad vecinal, ya sea por donación, ya sea como consecuencia de la usucapión, tal propiedad se presume libre de cargas. Especular acerca de si el presunto 
donante quiso imponer alguna carga o gravamen carece de una lógica jurídica. Si se carece de la base documental en la que conste fehacientemente que la transmisión de la propiedad iba acompañada de la imposición de una carga, se ha de presumir que la propiedad está libre de cargas, y el titular propietario ha de actuar en consecuencia.

Se ha afirmado, a efectos puramente especulativos, que de haber existido tal prohibición de disponer hubiera perdido eficacia por el paso del tiempo, o por la desaparición del interés justo y legítimo en que ha de basarse.

La conclusión es la misma que la del primer apartado, y que volvemos a reiterar. No parece adecuado, ni necesario, para resolver los problemas actuales proyectarse hacia el pasado lejano en la búsqueda de unos hipotéticos origenes de la situación actual. Las posibilidades de actuación sobre los terrenos vecinales no están condicionadas por su hipotético origen, y mucho menos por la voluntad del presunto donante, sino por la legislación actual que les sea aplicable en su condición de vecinales, o por los conflictos que se pudiesen plantear con respecto a los actuales poseedores de las fincas.

En definitiva, ninguno de los hipotéticos orígenes tiene trascendencia en el presente, por lo que el punto de partida para el análisis de los problemas actuales ha de ser la existencia de unas fincas vecinales con los criterios correspondientes respecto a la adjudicación, uso y disfrute, y facultades de disposición inter vivos y mortis causa por los vecinos.

\section{LA JUNTA VECINAL O PEDANÍA dE PONTEJOS COMO TITULAR DOMINICAL O PROPIETARIA DE LOS TERRENOS DE LAS «VECINDADES»}

Sitúese, por consiguiente, en el origen de la situación actual ya una titularidad enfitéutica, ya una donación, es indiscutible que a la altura de 1992 puede afirmarse de modo incontrovertible que sobre los terrenos de las "Vecindades» recae una titularidad de carácter dominical, un verdadero derecho de propiedad en sentido estricto. De optar, a efectos dialécticos, por la hipótesis de la constitución en su momento (1845, si hemos de creer al escrito del Presidente de la Junta Vecinal de Pontejos de 11 de noviembre de 1959) de un censo enfitéutico, en la actualidad, y a la vista de los antecedentes que obran en nuestro poder, dicha titularidad originaria se ha transformado, en virtud del mecanismo de la usucapión o prescripción adquisitiva (artículos 1940 y si- 
DICTAMEN ACERCA DE LA STTUACION JURIDICA EN QUE SE ENCUENTRAN LOS TERRENOS DE LAS 'VECINDADES

guientes del Código Civil), en una verdadera titularidad dominical o propietaria ex artículo 1647 del Código Civil, dada la inexistencia del reconocimiento por el dueño directo de su derecho (reconocimiento que debiera haberse producido cada veintinueve años, a fin de enervar la eventual prescripción adquisitiva, y cuya inexistencia puede sostenerse con suficiente fundamento).

Si (igualmente como hipótesis de trabajo) se parte de una inicial donación, la respuesta a la cuestión de la titularidad de los terrenos de las "Vecindades» es la misma que en la hipótesis anterior: la existencia de una auténtica titularidad dominical o propietaria vecinal (sin prejuzgar en este momento la concreta atribución de dicha titularidad), dada la virtualidad adquisitiva de la propiedad que tiene la donación (artículos 609 y 618 y siguientes del Código Civil). La eventual incorporación a la donación efectuada de una prohibición de disponer (cláusula que, por otro lado, no consta), sobre no surtir eficacia obstativa alguna a la adquisición de la propiedad, carecería en la actualidad de toda virtualidad ex artículos 781 y 785.2..$^{\circ}$ del Código Civil.

En todo caso, conviene salir al paso de la eventual objeción que a la adquisición (sucesiva en virtud del mecanismo de la usucapión) de una verdadera titularidad dominical o propietaria pudiera suponer, desde la perspectiva de la constitución de un censo enfitéutico como origen de la situación actual, la manifestación contenida en el escrito dirigido en 11 de noviembre de 1959 por el Presidente de la Junta Vecinal de Pontejos a la Abogacía del Estado en Santander. En dicho escrito se aludía, en efecto, a la existencia de una enfiteusis constituida en 1845 por el Sr. Marqués de Valdecarrana en favor de cincuenta y dos vecinos del pueblo de Pontejos, a fin de intentar eludir el pago de la deuda tributaria reclamada por el Impuesto de Personas Jurídicas. La finalidad de esta manifestación era, como puede comprenderse, clara: la alusión a la enfiteusis suponía el reconocimiento implícito del dominio directo en favor del constituyente de aquélla, el Marqués de Valdecarrana, a quien, en consecuencia, debía atribuirse la deuda tributaria derivada del hecho imponible que suponían la posesión y/o aprovechamiento de los terrenos cedidos en enfiteusis.

Mas, a la aludida manifestación del Presidente de la Junta Vecinal de Pontejos no cabe asignar en modo alguno el efecto implícitamente pretendido, cual la subsistencia de una mera titularidad enfitéutica vecinal. Y ello porque, constituida aquélla en 1845, en 1959, fecha de la citada manifestación, ya se había consumado el efecto anudado a la entrada en juego del mecanismo de la usucapión o prescripción adquisitiva, esto es, la adquisición de una verdadera titularidad propietaria. 
Consumado el efecto adquisitivo, resulta inocua la virtualidad enervante de aquél que pretende ligarse a la referida manifestación, tanto porque el eventual abandono de la propiedad requeriría una voluntad clara y terminante, indubitadamente formulada de modo expreso, como porque el Presidente de la Junta Vecinal (a salvo de hipotéticas habilitaciones en su favor por la comunidad vecinal, que no constan) carece manifestamente de competencia para producir una declaración de voluntad del tipo de la descrita. A mayor abundamiento, el mismo comportamiento de la Administración Tributaria, liquidando el Impuesto de Personas Jurídicas, se alinea en la posición de reconocer la existencia de una titularidad (propietaria) vecinal (y ello con independencia del concreto titular de este derecho de propiedad, los vecinos o la Junta Vecinal, cuestión irrelevante a estos efectos).

Así, pues, y en resumen, afirmación de una verdadera propiedad vecinal sobre los terrenos de las "Vecindades». Propiedad vecinal necesitada, en todo caso, de la determinación del concreto titular de la misma, cuestión que abordaremos seguidamente.

En este sentido, y como antes decíamos, no caben sino dos posibilidades, a saber: dicho titular es la Junta Vecinal de Pontejos, o, por el contrario, ha de predicarse la atribución de la propiedad de los terrenos comprendidos en las "Vecindades» de todos y cada uno de los poseedores/usuarios de aquéllos. De concluirse en la aseveración de la existencia de un conjunto de titularidades propietarias de que son titulares los actuales poseedores de los terrenos controvertidos, o las personas de que traen causa los derechos de éstos, resulta incontrovertible que la Junta Vecinal de Pontejos no ostenta título o potestad algunos en que fundar la determinación ulterior del destino de estos terrenos. Mas esta tesis adolece de la necesaria consistencia, tal y como mostraremos a continuación.

En efecto, y dando por bueno que el origen de la situación actual venga dada por la cesión operada en 1845, cesión producida, si hemos de atenernos a las propias manifestaciones de la Junta Vecinal, en favor de cincuenta y dos vecinos del pueblo de Pontejos, el destinatario último de aquella cesión no está constituido por los beneficiarios inmediatos de la misma, en cuanto titulares individuales, sino por aquéllos en tanto que miembros de la agrupación vecinal localizada en el pueblo de Pontejos. En otros términos, la aludida cesión (de uso, inicialmente, si bien en la actualidad transformada en una verdadera situación propietaria) se efectuó en atención a la consideración de "vecinos" del pueblo de Pontejos de las concretas personas beneficiarias de aquélla, 
DICTAMEN ACERCA DE LA STTUACIÓN JURIDICA EN QUE SE ENCUENTRAN LOS TERRENOS DE LAS "VECINDADES"

en atención a su pertenencia a una comunidad o agrupación especialmente localizada, el pueblo de Pontejos, en cuyo ámbito territorial resultaban comprendidos los terrenos que, aun con diversas denominaciones, se agrupan en las "Vecindades".

La referida comunidad o agrupación vecinal se expresa en la actualidad (y, cuando menos, desde 1931, fecha a que se retrotraen las actuaciones documentadas de la misma más antiguas que nos han sido facilitadas) mediante la forma jurídica de la Junta Vecinal, esto es, la entidad que asume la representación y defensa de los intereses peculiares de las poblaciones localizadas en el ámbito territorial a que se refiera la correspondiente comunidad o agrupación vecinal. Entidad que, a tenor de lo dispuesto en el artículo 3.2.a) de la vigente Ley Reguladora de las Bases del Régimen Local, Ley 7/1985, de 2 de abril, goza de la condición de entidad local. En concreto, el referido precepto se refiere a "las entidades de ámbito territorial inferior al municipal, instituidas o reconocidas por las Comunidades Autónomas, conforme al artículo 45 de esta Ley". Y el artículo 45 de la Ley Local señala en su número 1 que «las Leyes de las Comunidades Autónomas sobre régimen local regularán las Entidades de ámbito territorial inferior al Municipio, para la administración descentralizada de núcleos de población separados, bajo su denominación tradicional de caseríos, parroquias, aldeas, barrios, anteiglesias, concejos, pedanías, lugares anejos y otros análogos, o aquella que establezcan las Leyes». Por su parte, los artículos 38 a 45 y 53 del Texto Refundido de las Disposiciones Legales Vigentes en Materia de Régimen Local, aprobado por Real Decreto Legislativo 781/1986, de 18 de abril, concretan diferentes extremos relativos al régimen jurídico de estas Entidades Locales de ámbito territorial inferior al municipal.

La defendida atribución de los terrenos aquí considerados a la Junta Vecinal o Pedanía de Pontejos, y no a sus integrantes vecinos en cuanto beneficiarios directos del aprovechamiento de aquellos terrenos, no debe sin embargo conducirnos a la conclusión equivocada de afirmar una separación o contraposición tajante y radical entre la Junta Vecinal o Pedanía, en cuanto formalización jurídica de una comunidad o agrupación vecinal, expresada en un centro individualizado de imputación en virtud de la técnica de la personificación, y los vecinos agrupados en la comunidad de que es expresión jurídica la Junta Vecinal o Pedanía. Y ello porque históricamente, hasta bien entrado el siglo XIX, no ha existido conciencia, especialmente en las comunidades vecinales más pequeñas, de la interposición (menos aún si era de carácter personificado, tal y como modernamente concebimos este arbitrio técnico de la personificación) entre los vecinos y los bienes que éstos utilizaban o 
aprovechaban, de una entidad cualitativamente diferenciada de aquéllos, depositaria de unos intereses distintos de los que eran portadores los propios vecinos, y cuyas determinaciones, como estructura administrativa, se impusieran coactivamente a los vecinos mismos. Antes bien, aquella estructura administrativa (en nuestro caso, la Junta Vecinal o Pedanía) no pasaba de ser una mera instancia organizadora de los criterios de aprovechamiento y utilización de los patrimonios colectivos vecinales, en virtud de la aplicación de unas normas (simples, en cualquier caso) aprobadas por todos los vecinos reunidos, de acuerdo con la periodicidad fijada al efecto, en Concejo. La sencillez de la realidad socieconómica, la dispersión de las poblaciones (especialmente visible en el Norte de España) y los fuertes vínculos de carácter comunitario, en cuanto fenómenos que están en la base de este peculiar modo de organización de la vida vecinal, no exigían otros modos de organización de la convivencia colectiva que los fundados en una intensa participación de todos los vecinos en la determinación de las condiciones de vida de la comunidad vecinal y el establecimiento en régimen de autoorganización de unas sencillas reglas de distribución de los aprovechamientos vecinales, cuyo aseguramiento se encomendaba a una instancia (en modo alguno separada de la propia realidad vecinal) que, con el devenir histórico, y con independencia de su denominación, adquiriría el carácter de verdadera estructura administrativa, aglutinadora de los intereses peculiares de los vecinos agrupados en una comunidad especialmente localizada, incluso dotada de personalidad jurídica, según el concepto y la función que esta noción tiene en el mundo del Derecho Público.

En síntesis, el carácter estrictamente artificial de estas instancias o estructuras representativas de los intereses locales de una comunidad vecinal (máxime de las más reducidas en población y territorio), no debe hacer olvidar que la Junta Vecinal o Pedanía, como entidad que asume la representación y defensa, especialmente de los de índole patrimonial, de los intereses vecinales, se configura como verdadero centro de imputación, dotado de personalidad jurídica, y titular, por lo que aquí interesa, en concepto de titular dominical o propietario, de los terrenos cuyo aprovechamiento y utilización son encomendados a los vecinos. En cuanto propietario de unos bienes vecinales, la Junta Vecinal o Pedanía incorpora un conjunto de facultades o potestades relacionadas con el ordenado uso de aquéllos (normas sobre utilización de los terrenos, adjudicación de los oportunos lotes o suertes, criterios sobre sucesión en el aprovechamiento de los bienes, otorgamiento de la condición de "vecino" a efectos de poder participar en los otorgamientos colectivos,...), de cuyo ejercicio constan sobradas muestras en la documentación aportada por la Junta Vecinal de Pontejos, y 
que no son sino expresión de la cualidad de verdadero titular dominical o propietario que aquélla ostenta sobre los terrenos de las «Vecindades». A mayor abundamiento, esta cualidad de propietario de que es titular la Junta de Pontejos queda refrendada por la actitud de los propios vecinos, respetuosos con la titularidad dominical de la Junta, y conscientes de que la que a ellos corresponde es una mera facultad de uso o aprovechamiento (a la cual es ajena el animus domini), tal y como evidencian todas y cada una de las veces en que, en relación con las diversas vicisitudes atinentes al estatuto jurídico de los terrenos de las "Vecindades», se han dirigido a la Junta, ya para impetrar la condición de "vecino", a efectos de poder participar en los aprovechamientos colectivos, ya para solicitar la adjudicación de los oportunos lotes, según las normas establecidas (de las que es expresivo un escrito de 17 de enero de 1845, que transcribe el decreto dado en la parroquia de Pontejos por el entonces Alcalde de la misma). Comportamiento, pues, de los vecinos inexplicable jurídicamente de sostenerse que aquéllos eran los titulares dominicales o propietarios de los terrenos de las "Vecindades", tesis incorrecta, y que, en consecuencia, ha de ser desechada, afirmando, por tanto, la existencia de un verdadero derecho de propiedad de la Junta Vecinal o Pedanía de Pontejos sobre los referidos terrenos.

\section{LA CALIFICACIÓN JURÍDICA DE LOS TERRENOS DE LAS "VECINDADES" COMO BIENES COMUNALES: PROPIEDAD PÚBLICA Y APROVECHAMIENTO COMUNAL}

Afirmación, pues, de la titularidad, en concepto de titularidad dominical o propietaria, de los terrenos de las "Vecindades" por parte de la Junta Vecinal o Pedanía de Pontejos. Y titularidad que ha de ser sostenida sin perjuicio de afirmar, igualmente, el derecho de uso y aprovechamiento que sobre aquéllos corresponde a los vecinos del pueblo de Pontejos. Corresponde ahora, en consecuencia, determinar la naturaleza jurídica de los referidos bienes, y por ende, la posición o status que en relación con los mismos es predicable, por un lado, de la Junta Vecinal, como titular propietario, y, por otro, de los vecinos, en cuanto beneficiarios directos de las utilidades dispensadas por dichos bienes.

En este sentido, y respecto de la concreta cuestión propuesta, se impone, no ya como mera exigencia metodológica sino como imperativo de orden sustantivo o material, realizar una precisión análoga a la efectuada en el epígrafe anterior a propósito de la determinación de la concreta titularidad (dominical o propietaria, no se olvide) de los terrenos que nos ocupan. En efecto, en aquel momento concluíamos 
(sin perjuicio de afirmar la existencia de un verdadero derecho de propiedad en favor de la Junta Vecinal o Pedanía de Pontejos) en la improcedencia de utilizar categorías dogmáticas de uso frecuente en la actualidad (cual la de personalidad jurídica, como arbitrio técnico fundador de un centro de imputación, especialmente en los aspectos estrictamente patrimoniales), a fin de preconizar la atribución a una organización, personificada y entitativamente diferenciada de la comunidad o agrupación vecinal que está en su base, a título de propiedad, de un patrimonio vecinal, respecto del cual los integrantes de aquélla o vecinos no ostentarían sino un mero derecho de uso o aprovechamiento. Quiere decirse que, con independencia de la identificación de un concreto titular (respecto de cuya particular localización no cabe en la actualidad duda alguna), la específica realidad de las poblaciones vecinales situaba en primer plano un determinado modo de utilización y aprovechamiento de los patrimonios colectivos vecinales, cuyas utilidades (al margen formales atribuciones de propiedad, extremo en todo caso accesorio) habrían de revertir, como sustrato socio económico característico de sistemas escasamente desarrollados, a las poblaciones que se erigían en destinatarios últimos de aquellos patrimonios, cuya administración se encomendaba a la instancia representativa de los intereses de dichas poblaciones, en nuestro caso la correspondiente Junta Vecinal o Pedanía.

Pues bien, y a propósito de la concreción de la naturaleza jurídica de los terrenos de las "Vecindades», propiedad de la Junta Vecinal de Pontejos, es preciso prescindir de todo apriorismo de carácter dogmático que nos fuerce a encorsetar la calificación y consiguiente régimen jurídico de los bienes aquí considerados en alguna de las categorías que el moderno Derecho de los bienes públicos ha sistematizado para dar explicación de la variada y multiforme realidad patrimonial de los entes públicos. Precisamente, es en el ámbito local en el que se localiza la más completa y acabada sistematización de los bienes públicos, hasta el punto de haberse podido afirmar. que el Reglamento de Bienes de la Entidades Locales (tanto en su versión de 1955 como en la de 1986) constituye el verdadero código unitario de los bienes de dominio público (una de las categorías, por cierto, en que se agrupan los bienes integrantes de los patrimonios públicos), justamente por la carencia en la regulación estatal de una sistematización unitaria que aglutine el régimen jurídico de los llamados bienes de dominio público. Por cierto que, desde otro punto de vista, la aludida sistematización unitaria del Derecho de los bienes locales, expresión, quizá exacerbada, de un dogmatismo reductor a esquemas cerrados de una realidad compleja que no siempre resiste las pretensiones totalizadoras propias de planteamientos en exceso juridicistas, dicha sistematización, se insiste, puede 
DICTAMEN ACERCA DE LA STTUACION JURIDICA EN QUE SE ENCUENTRAN LOS TERRENOS DE LAS "VECINDADES"

conducir a soluciones rígidas y poco dúctiles cuando de aprehender un mundo tan vivo como el de los patrimonios vecinales y el sustrato socioeconómico que está en su base se trata. Sirvan, pues, estas someras consideraciones para intentar enmarcar más adecuadamente la calificación y régimen jurídico que en la actualidad quepa atribuir a los terrenos de las «Vecindades», del pueblo de Pontejos.

El artículo 183 del Texto Articulado y Refundido de las Leyes de Bases de Régimen Local de 17 de julio de 1945 y 3 de diciembre de 1953, aprobado por Decreto de 24 de junio de 1955 (abreviadamente, Ley de Régimen Local de 1955), procedió a clasificar los bienes municipales de acuerdo con el básico criterio de la afectación. Los bienes municipales, decía aquel precepto, «se clasifican en bienes de dominio público y bienes patrimoniales. Los bienes de dominio público son de uso o servicio público; los patrimoniales son de propios o comunales». Los artículos 184 a 187 definieron lo que había de entenderse por cada una de las cuatro anteriores categorías de bienes, prescribiéndose en el artículo 188 que «los bienes de dominio público, mientras conserven este carácter, y los comunales, serán inalienables, imprescriptibles e inembargables, y no estarán sujetos a tributación del Estado». El Reglamento de Bienes de las Entidades Locales de 27 de mayo de 1955, como antes se dijo, desarrolló pormenorizadamente la clasificación y régimen jurídico de los bienes locales. El vigente Derecho local mantiene sustancialmente los criterios clasificatorios expuestos, no obstante introducir alguna innovación (de escasa trascendencia práctica, por lo demás) respecto de la calificación jurídica de los bienes comunales. Así, el artículo 79.2 de la Ley de Bases de Régimen Local de 1985 dice que «los bienes de las Entidades locales son de dominio público o patrimoniales», señalándose en el número 3 de este artículo 79 que «son bienes de dominio público los destinados a un uso o servicio público. Tienen la consideración de comunales aquéllos cuyo aprovechamiento corresponda al común de los vecinos». Y en el artículo 80.1 que «los bienes comunales y demás bienes de dominio público son inalienables, inembargables e imprescriptibles y no están sujetos a tributo alguno». Precisamente, de la dicción de este artículo 80.1 se desprende que en la actualidad los bienes comunales tienen formalmente la calificación de bienes de dominio público, a cuyo régimen jurídico, obviamente, se someten. En todo caso, y como antes indicamos, aun bajo la calificación de bienes patrimoniales, los comunales se sujetaban, según la legislación anterior a 1985 (artículo 188 de la Ley de Régimen Local de 1955), a idéntico régimen que el prescrito para los de dominio público. Por su parte, los artículos 74 a 84 del Texto Refundido de las Disposiciones Legales vigentes en materia de Régimen Local de 1986, incorporan las determinaciones sobre bienes locales de la antigua legislación 
de 1955. El sistema de fuentes en este ámbito se completa, finalmente, con el Reglamento de Bienes de las Entidades Locales de 1986, aprobado por el Real Decreto 1372/1986, de 13 de junio, que sustituye al anterior de 1955, actualizando las disposiciones de éste último, si bien inspirándose en criterios análogos a los asumidos por aquél.

La precisión, por tanto, de la naturaleza jurídica de los terrenos de las «Vecindades» (y ha de notarse incidentalmente que la dicción del vigente artículo 79 de la Ley Local de 1985, con su referencia a las Entidades locales, de cuyo patrimonio se ocupa, es más comprensiva, y correcta, que la del viejo artículo 183 de la Ley de 1955, como la del 182 de esta misma Ley, que únicamente aludía al patrimonio o a los bienes de las Entidades municipales, concreción que obvia cualquier dificultad en relación con la atribución de titularidades propietarias a Entidades de ámbito territorial inferior al municipal, en nuestro caso a la Junta Vecinal o Pedanía de Pontejos), la referida precisión, decíamos, ha de partir necesariamente de la aludida flexibilidad con que han de ser aplicadas las categorías jurídicas (en el presente supuesto, las relativas a la clasificación de los bienes locales) en la explicación de la titularidad y aprovechamiento de los patrimonios vecinales. $\mathrm{Y}$ ello porque, hasta fechas bien recientes (la segunda mitad del siglo XIX, por ensayar una localización espacial), los indicados patrimonios vecinales constituían una masa indiferenciada de bienes, cuya utilización y disfrute eran entregados a las respectivas poblaciones vecinales, sin otra intermediación, a lo sumo, y en estadios más o menos evolucionados de la organización pública, que la mera interposición de una entidad, progresivamente personificada, representativa del común de los vecinos y llamada a establecer las reglas sobre distribución de los citados aprovechamientos vecinales. Con el devenir histórico, sobre aquella común y homogénea masa indiferenciada de bienes locales, se monta una diferenciación, en sí misma artificial y obediente a los concretos y convencionales intereses de los correspondientes grupos vecinales, fundada en la diferente afectación o destino de los respectivos bienes, básicamente la relativa a la distinción entre bienes de propios (cuya virtualidad esencial era la de nutrir las arcas locales, mediante el otorgamiento exclusivo de su aprovechamiento a algún vecino; así, artículos 186 y 673.2.c) de la Ley de Régimen Local de 1955 y 5.2.a) del Reglamento de Bienes de 1955) y bienes comunales (aquéllos cuyo aprovechamiento y disfrute pertenecen al común de los vecinos «exclusivamente», en la expresiva dicción de los artículos 187 de la Ley Local de 1955 y 5.2.b) del Reglamento de Bienes de 1955). En todo caso, como se ha señalado, ha de tenerse en cuenta que la indicada distinción no obedecía a razón sustancial alguna, viniendo determinada 
por motivos estrictamente aleatorios y coyunturales, como lo prueba el hecho de la permanente comunicación y trasvase entre unos y otros bienes, que provocaba la atribución de diferentes calificaciones jurídicas en función de la conveniencia y necesidades de las respectivas poblaciones vecinales (así, significadamente, el intento de eludir en la medida de lo posible la impresionante operación de venta forzosa puesta en marcha mediante la Ley desamortizadora de 1 de Mayo de 1855 , la conocida como Ley Madoz, y que afectó a los en el momento de su entrada en vigor calificados como bienes de propios de los pueblos). Por otro lado, y una vez consolidado el dogma de la personalidad jurídica de los entes locales (fundamentalmente, de los Municipios), que tuvo como consecuencia la erección de una entidad diferenciada de las poblaciones vecinales (que, naturalmente, constituían su soporte personal), dotada de intereses cualitativamente distintos de los de los vecinos, se afirmará progresivamente, siempre sobre el común denominador de la atribución de su titularidad al correspondiente ente local personificado, una nítida separación de regímenes jurídicos, que, acompañada a su vez de una mayor tecnificación en la clasificación de los bienes locales (esto es, el afianzamiento de la summa divisio en materia de bienes locales, la que distingue entre bienes de dominio público y bienes patrimoniales), conducirá a individualizar como categoría autónoma dentro de los bienes locales lo que en su origen no fue sino, repetimos, un conjunto homogéneo e indiferenciado de bienes, esto es, los hoy denominados bienes comunales (patrimoniales, según la legislación local de 1955; de dominio público, de acuerdo con la normativa inaugurada en 1985), cuyo rasgo distintivo o nota sustantivadora radica, según hemos precisado con anterioridad, en la atribución de su aprovechamiento al común de los vecinos, sin perjuicio de sostener la titularidad del correspondiente ente vecinal (artículos 79.3 de la Ley Local de 1985, 75 del Texto Refundido de 1986 y 2.3 del Reglamento de Bienes de 1986).

Pues bien, dentro de la prudencia y cuidado con que han de ser manejadas las categorías jurídicas, especialmente en su aplicación a realidades de hondo arraigo histórico, no parecen existir serios inconvenientes a la hora de atribuir la calificación de bienes comunales a los terrenos comprendidos en las «Vecindades», en el pueblo de Pontejos, Municipio de Marina de Cudeyo. Calificación que, a tenor de lo señalado, y excluida por improcedente toda tentativa de aplicar a los mismos el régimen de los denominados montes vecinales en mano común (hoy regidos por la Ley 55/1980, de 11 de noviembre, derogatoria de la 52/1968, de 27 de julio, y aludidos en el artículo 83 de la Ley de Bases de Régimen Local de 1985), es la que mejor se acomoda 
al estatuto peculiar de aquellos bienes y la más adecuada a su régimen de utilización y disfrute (titularidad del ente vecinal y aprovechamiento por los vecinos). En todo caso, ha de tenerse en cuenta, como igualmente hemos indicado con anterioridad, que en la actualidad los bienes comunales tienen formalmente la condición de bienes de dominio público (inalienables, inembargables e imprescriptibles, siempre y cuando, naturalmente, conserven este carácter, como con toda corrección precisaba el artículo 188 de la Ley de Régimen Local de 1955), circunstancia que impone la necesaria alteración de su calificación jurídica de pretenderse un cambio de afectación o destino de los mismos (artículo 81 de la Ley de Bases de 1985 y 8 del Reglamento de Bienes de 1986).

\section{RÉGIMEN JURÍDICO DE LOS TERRENOS DE LAS "VECINDADES" Y POSIBILIDADES DE TRANSFORMACIÓN EVOLUTIVA DE LOS MISMOS}

Titularidad dominical o propietaria de la Junta Vecinal o Pedanía de Pontejos sobre los terrenos de las «Vecindades», pues. Atribución, por otro lado, a los referidos terrenos de la calificación de bienes comunales, calificación que supone, amén de su condición de bienes de dominio público (y no ha de olvidarse que los bienes comunales sólo pueden pertenecer a los Municipios y a las Entidades locales menores ex artículo 2.4 del Reglamento de Bienes de 1986), la entrega de su aprovechamiento al común de los vecinos. Tal es, en síntesis, el resumen de las consideraciones vertidas en los epígrafes anteriores, en cuanto respuestas a las dos primeras cuestiones que nos habíamos propuesto (epígrafe II, in fine). Resta, por consiguiente, abordar el tercero de los grandes temas (en el cual, a su vez, se subsumen las cuestiones 3 a 7 planteadas en el escrito de la Junta Vecinal de Pontejos de 10 de marzo de 1992) entonces suscitados, esto es, el relativo al "régimen jurídico a que se sujetan estos terrenos, $y$, en consecuencia, posibilidades de actuación respecto de los mismos».

El punto de partida ha de estar constituido, necesariamente, por el recordatorio de la naturaleza jurídica de los terrenos que nos ocupan, naturaleza que no es otra sino la de su condición de bienes comunales. Bienes cuya calificación formal es en la actualidad, repetimos, la de bienes de dominio público, sin perjuicio de que su disfrute y aprovechamiento se hallen atribuidos a los vecinos (id est, a los integrantes de la comunidad cuya representación asume la entidad titular de los bienes). Precisamente, esta última característica es la que singulariza el estatuto jurídico de los comunales, expresión, aun con todas 
DICTAMEN ACERCA DE LA STTUACIÓN JURIDICA EN QUE SE ENCUENTRAN LOS TERRENOS DE LAS "VECINDADES"

las connotaciones de residuo histórico que quieran apreciarse, de formas de vida comunitarias, basadas en el aprovechamiento directo por los vecinos de los patrimonios colectivos vecinales. De ahí que, consecuente con este planteamiento, el artículo 75.1 del Texto Refundido de 1986 diga que «el aprovechamiento y disfrute de bienes comunales se efectuará preferentemente («precisamente» es el adverbio utilizado por el artículo 94.1 del Reglamento de Bienes de 1986) en régimen de explotación colectiva o comunal». De resultar impracticable este aprovechamiento y disfrute de bienes comunales ("general simultáneo»), continúa el artículo 75.2 del mismo Texto Refundido, habrá de estarse a la costumbre u Ordenanza local al respecto, y, en defecto de éstas, habrán de efectuarse adjudicaciones de lotes o suertes a los vecinos (en sentido idéntico, artículo 94.2 del Reglamento de Bienes de 1986). En último término, de ser imposibles las anteriores formas de aprovechamiento y disfrute, podrán autorizarse adjudicaciones en pública subasta, mediante precio, en las formas y condiciones a que se refieren los artículos 75.3 del Texto Refundido de 1986 y 94.3 del Reglamento de Bienes de 1986.

El descrito régimen de aprovechamiento de los bienes comunales, trasunto en último término de formas de vida hoy quizá superadas, sin perjuicio de las potencialidades que de estos patrimonios vecinales puedan extraerse mediante un adecuado y racional sistema de explotación económica, el citado régimen, decíamos, en la medida en que impone un muy concreto destino a estos bienes (su afectación comunal, aun con las diversas variantes antes aludidas en cuanto a las distintas formas de adjudicación de los aprovechamientos), puede conducir a una evidente rigidificación y encorsetamiento en la utilización de estas masas patrimoniales, petrificando el desarrollo económico de las poblaciones vecinales. Pues bien, justamente para evitar esta no deseada consecuencia, incompatible por lo demás con el signo de los tiempos, la calificación actualmente atribuida a los comunales, como bienes de dominio público, encierra virtualidades superadoras de la referida situación. En concreto, la indubitada titularidad en favor de la entidad propietaria (la Junta Vecinal o Pedanía de Pontejos, en el supuesto considerado), titularidad en concepto de dominio público, permite a aquélla, una vez cumplimentados los trámites oportunos (artículo 8 del Reglamento de Bienes de 1986), otorgar a los terrenos en cuestión el destino que se juzgue más conveniente en función de las necesidades de la población afectada, sin tener por ello que sujetarse necesariamente a su afectación natural, la comunal, y supeditarse, en consecuencia, al régimen de aprovechamiento legalmente previsto (artículo 75 del Texto Refundido de 1986 y artículos 94 y siguientes del Reglamento de Bienes de 1986). Esto es, la citada condición demanial permite, ya el mantenimiento del carácter comunal 
de los bienes en cuestión (con sujeción a las antes señaladas prescripciones legales y reglamentarias en materia de disfrute y utilización, y, por remisión implícita de las mismas, a las normas, convencionales o consuetudinarias, tradicionalmente rectoras de los aprovechamientos vecinales), ya la desafectación de los mismos, y su conversión en bienes patrimoniales (de propios) de la entidad representativa de los intereses vecinales (la Junta Vecinal o Pedanía). Posibilidad esta última que otorga a la correspondiente entidad administrativa las más amplias facultades en cuanto a la disponibilidad del destino ulterior de los terrenos afectados, y cuyo desenvolvimiento, al hilo de las cuestiones planteadas por la Junta Vecinal de Pontejos, describiremos seguidamente.

\section{Mantenimiento del carácter comunal de los terrenos de las «Vecindades»}

La permanencia de la condición de bienes comunales de los terrenos aquí considerados, sin merma de la titularidad dominical o propietaria en favor de la Junta Vecinal o Pedanía de Pontejos, implica el mantenimiento del régimen de aprovechamiento típico o peculiar de los comunales, es decir, su utilización y disfrute por el común de los vecinos. Régimen de aprovechamiento que, en el caso presente, supone la pertinente adjudicación de los oportunos lotes o suertes a los vecinos, de conformidad con las normas que han venido rigiendo las correspondientes adjudicaciones, y sin perjuicio, obviamente, de la posibilidad de modificar las citadas normas, de acuerdo con el procedimiento seguido al efecto, a fin de acomodar los respectivos aprovechamientos al sistema que se juzgue más conveniente por la población integrada en la Junta Vecinal o Pedanía.

Consecuentemente, el mantenimiento del indicado modo de explotación de los terrenos de las "Vecindades» (en concepto de comunales, no se olvide), supone que el pueblo de Pontejos, a través de su entidad representativa más cercana, la Junta Vecinal o Pedanía, titular de los indicados terrenos, puede libérrimamente mantener o modificar las condiciones de acceso al disfrute y aprovechamiento de los bienes considerados. En particular, puede exigir especiales condiciones de arraigo, vinculación o permanencia a fin de participar en los aprovechamientos de los terrenos en cuestión, pudiendo, en consecuencia, apartar del acceso a aquellos aprovechamientos a las personas que no acrediten las citadas condiciones de arraigo, vinculación o permanencia y, más en concreto, a aquéllas cuyo domicilio no radique ya en el pueblo de Pontejos, al menos desde hace un número importante de años (cuestión 7 de las planteadas en el escrito de la Junta Vecinal de Pontejos de 10 de marzo de 1992). 
DICTAMEN ACERCA DE LA STIUACIÓN JURfDICA EN OUE SE ENCUENTRAN LOS TERRENOS DE LAS 'VECINDADES"

\section{Desafectación del carácter comunal de los terrenos de las «Ve- cindades" y otorgamiento de un nuevo destino bajo la condi- ción de dominio público}

La pérdida del carácter comunal de los terrenos de las «Vecindades» (esto es, su desafectación del aprovechamiento común de los vecinos), y su afectación a un nuevo destino de uso o servicio público (alteración de la calificación jurídica sujeta en todo caso a las prescripciones del artículo 8 del Reglamento de Bienes de 1986), constituye una posibilidad de la Junta Vecinal o Pedanía de Pontejos, en cuanto titular propietario de los terrenos considerados. Posibilidad siempre abierta que, en cualquier caso, exigiría la previa identificación del nuevo destino público (un uso o servicio público ex artículos 79.3 de la Ley de Bases de Régimen Local de 1985, 74 del Texto Refundido de 1986, 2.2, 3 y 4 del Reglamento de Bienes de las Entidades Locales de 1986), como condición necesaria para proceder a la nueva afectación de los bienes.

\section{Desafectación del carácter comunal de los terrenos de las "Ve- cindades" y su conversión en bienes patrimoniales (de pro- pios) de la Junta Vecinal o Pedanía}

La pérdida del carácter comunal de los terrenos objeto de esta consulta, y la consiguiente alteración de su calificación jurídica, puede hacerse, no ya mediante el otorgamiento a aquéllos de un nuevo destino de uso o servicio público (mantenimiento del carácter de dominio público de los mismos), sino mediante su conversión en bienes patrimoniales o de propios de la Junta Vecinal o Pedanía de Pontejos, con sujeción, en todo caso, a los requisitos al efecto establecidos en el artículo 8 del Reglamento de Bienes de 1986. La indicada posibilidad de conversión en bienes patrimoniales o de propios, cuyo fundamento jurídico es, repetimos, la titularidad dominical o propietaria que sobre los mismos ostenta la Junta Vecinal de Pontejos, otorga a esta última las más amplias facultades en cuanto a la disponibilidad de estos terrenos (artículos 76 del Texto Refundido de 1986 y 6 del Reglamento de Bienes de 1986). En consecuencia:

- Una vez producida la indicada conversión en bienes patrimoniales o de propios, ningún obstáculo se alza para que la Junta Vecinal o Pedanía de Pontejos pueda enajenar los lotes o suertes de las «Vecindades" de que actualmente son adjudicatarios los vecinos del pueblo de Pontejos. Dicha enajenación podrá efectuarse (mediante subasta 
pública ex artículo 80 del Texto Refundido de 1986 y 112 del Reglamento de Bienes de 1986) tanto en favor de los actuales poseedores de los correspondientes lotes o suertes, o en favor de terceros no poseedores, en los términos y con sujeción a las condiciones establecidas por la Junta Vecinal. En el indicado procedimiento de enajenación, en principio, y siempre a salvo de lo que puedan disponer las condiciones rectoras de aquél, fijadas por la Junta Vecinal, no ostentan preferencia alguna para ser adjudicatarios los actuales poseedores de los terrenos de las «Vecindades».

En todo caso, ha de tenerse en cuenta que la enajenación habrá de sujetarse a lo dispuesto en los artículos 79 del Texto Refundido de 1986 y 109 del Reglamento de Bienes de 1986. Así, la indicada enajenación habrá de comunicarse (se entiende, a través del Ayuntamiento de Marina de Cudeyo, al cual pertenece el pueblo de Pontejos) al órgano competente de la Comunidad Autónoma. Si el valor de los terrenos enajenados excediera del 25 por 100 de los recursos ordinarios del presupuesto anual de la Corporación (y por Corporación habrá de entenderse en buena lógica la Junta Vecinal o Pedanía de Pontejos), la enajenación requerirá autorización del pertinente órgano de la Comunidad Autónoma.

De este modo, pueden considerarse cumplimentadas las cuestiones formuladas bajo los números 3 y 4 del escrito de la Junta Vecinal de Pontejos de 10 de marzo de 1992.

- Las amplias facultades de disposición que se derivan para la Junta Vecinal de Pontejos de la conversión en bienes patrimoniales o de propios de los terrenos de las "Vecindades", permiten dar asimismo cumplida respuesta a la cuestión suscitada con el número 6 en el antes indicado escrito de 10 de marzo de 1992, esto es, la viabilidad de «modificar la configuración de los lotes con carácter previo a la posible enajenación». Orientada o no a una futura venta, la alteración de la calificación jurídica de los terrenos considerados, en virtud de la aludida conversión en bienes patrimoniales o de propios, conlleva la desaparición de los aprovechamientos comunales hasta entonces recayentes sobre aquéllos y, en consecuencia, la desaparición de los «lotes" o «suertes" en que actualmente se cifra el sistema de adjudicación de los aprovechamientos sobre los citados terrenos, que pasarían así a integrarse en el patrimonio de la Junta Vecinal como una masa patrimonial indiferenciada (sin perjuicio, claro está, de su concreta localización espacial), respecto de la cual aquélla, como titular dominical o propietaria podría disponer según estimara más oportuno o conveniente. 
- La cuestión formulada bajo el número 5 en el escrito de 10 de marzo de 1992 ( posibilidades de poner fin al derecho de los poseedores en los suelos calificados como urbanos»), amén de la indeterminación finalista con que aparece redactada (no es fácil discernir, en efecto, cuál sea la intención con que la misma es dirigida a nosotros, pues, con independencia de la respuesta que a aquélla se dé, tanto puede encubrir el designio de desapoderar a sus actuales poseedores de los terrenos en cuestión, en favor de la Junta Vecinal, sin que el citado desapoderamiento vaya seguido de una eventual enajenación, como puede referirse, por el contrario, al deseo de proceder a la venta de estos terrenos exclusivamente, marginando del procedimiento de enajenación a los terrenos no clasificados según el vigente planeamiento como urbanos), amén de esta apostilla, insistimos, la formulación de esta cuestión suscita una serie de problemas si la citada operación (legítima, en principio, y sin perjuicio de lo que a continuación se dirá) es emprendida con carácter singular, al margen de las actuaciones que puedan llevarse a cabo en relación con los terrenos que no tienen la clasificación de urbanos.

En efecto, aun cuando la titularidad propietaria que la Junta Vecinal de Pontejos ostenta sobre todos y cada uno de los terrenos comprendidos en las «Vecindades», permite a aquélla actuar de modo singularizado en relación con aquéllos (atendiendo, así, entre otros extremos, a la diferente clasificación urbanística que los mismos posean), no debe olvidarse que, tanto en su origen como en su devenir histórico, la suerte de estos terrenos ha estado indisolublemente ligada al destino de las poblaciones vecinales existentes en cada momento, constituyendo de este modo una especie de patrimonio común, si no unitario, al menos homogéneo. No quiere decirse con esto que, jurídicamente, la Junta Vecinal de Pontejos no pueda tomar en consideración un hecho diferencial tan destacado como la distinta clasificación urbanística de los terrenos (determinación, por lo demás, en modo alguno debida a la historia o al carácter comunal de estos bienes, sino única y exclusivamente a la decisión, en sí misma artificial y convencional, del planeador urbanístico), a fin de proceder de modo separado e individualizado en función de la naturaleza urbana o no urbana de los terrenos. Más aún, y siempre y cuando se inscriba en una operación global o de conjunto, que afecte a todos los terrenos de las «Vecindades», la toma en consideración de la clasificación urbanística recayente sobre cada terreno debe erigirse en elemento inexcusable de referencia de cara a una eventual "redistribución" (de acuerdo con la fórmula que los vecinos reunidos en Concejo estimen más oportuna) de las utilidades dimanantes en estos terrenos. Mas estas mismas apreciaciones, en su 
misma entidad, llevan a desaconsejar una actuación exclusivamente ceñida al desapoderamiento de los actuales tenedores de terrenos clasificados como urbanos ( $\mathrm{y}$, una vez más, hemos de insistir en que la cuestión planteada por la Junta Vecinal de Pontejos, bajo el número 5, en su escrito de 10 de marzo de 1992, en su misma indeterminación encierra una serie de interrogantes, no reflejados de modo expreso, acerca de los cuales no es oportuno pronunciarse, pues toda opinión que al respecto vertiéramos, fuera de las consideraciones que anteceden, no traspasaría el umbral del mero juicio hipotético de intenciones). En suma, pues, y según expondremos en los epígrafes siguientes, las actuaciones que pretendan llevarse a cabo sobre los terrenos de las «Vecindades» deben emprenderse desde una visión global o de conjunto, a fin de impedir eventuales impugnaciones (vulneración del principio de igualdad, desviación de poder,...) por parte de los afectados, y, sobre todo, con la finalidad de evitar introducir diferencias de trato, que, aun cuando no sean en sí mismas discriminatorias, suscitan el recelo que conlleva la aplicación de consecuencias distintas a supuestos, en principio, iguales, recelo que se vería incrementado en casos, como el presente, de grupos vecinales reducidos, tradicionalmente aglutinados en torno a intereses económicos comunes.

\section{EL PESO DE LA HISTORIA COMO CONDICIONANTE DE LAS POSIBILIDADES DE TRANSFORMACIÓN EVOLUTIVA DE LOS TERRENOS DE LAS «VECINDADES»}

La historia condiciona las realidades presentes, mas la historia ni constituye una pétrea entidad monolítica, ni, menos aún, impone, o debe imponer, sus dictados al socaire de virtudes quintaesenciadas más o menos mixtificadas. Los bienes comunales, expresión socioeconómica de formas de vida comunitarias, que hunden sus raíces poco menos que en la noche de los tiempos, representan un marco de referencia inexcusable a la hora de entender el estado actual de los bienes locales, mas ni su trascendencia económica es hoy la de antaño (a despecho de su revitalización imaginativa, que permita encauzar ordenadamente el desarrollo económico de determinadas poblaciones vecinales), ni su configuración jurídica (el aprovechamiento comunal de los vecinos, no obstante la atribución de su titularidad dominical a la entidad local representativa) debe hipotecar, so capa de un pretendido halo romanticista, las posibilidades configuradoras, atentas al designio de los nuevos tiempos, del ente titular de estos bienes, la organización personificada local. Esta última precisión, como más arriba advertimos, halla su viabilidad procedimental en el cauce de la 
DICTAMEN ACERCA DE LA STTUACIÓN JURIDICA EN QUE SE ENCUENTRAN LOS TERRENOS DE LAS 'VECINDADES

calificación jurídica actual de los comunales, esto es, la atribución de su titularidad en concepto de dominio público, conceptuación que, una vez cumplimentados los requisitos pertinentes (artículo 8 del Reglamento de Bienes de 1986), hace posible la alteración de su calificación jurídica (id est, el establecimiento de una nueva afectación, con mantenimiento del carácter de dominio público, o, más intensamente aún, la conversión en bien patrimonial o de propio de la entidad local), alteración que otorga las más amplias disponibilidades en favor de la entidad titular de los bienes, tal y como más arriba expusimos (epígrafe VIII, 1, 2 y 3).

Pues bien, supuestas (y existentes) las posibilidades jurídicas de obrar, en el sentido de una transformación evolutiva de la situación de los terrenos de las «Vecindades», en manos de la Junta Vecinal de Pontejos, la efectiva realización de la indicada transformación, únicamente dependerá de la concreta voluntad de la población vecinal afectada, expresada a través de su entidad representativa, la Junta Vecinal o Pedanía de Pontejos. Transformación evolutiva que, sin perjuicio de su sentido último, ha de tomar en consideración una serie de condicionantes y precisiones.

Condicionantes y precisiones que derivan en buena medida de los diferentes extremos contenidos en el denominado "Breve informe técnico relativo al "valor medio de los terrenos de las Vecindades del pueblo de Pontejos", Municipio de Marina de Cudeyo, Región de Cantabria», suscrito en 6 de julio de 1992 por el Técnico Municipal del Ayuntamiento de Marina de Cudeyo. Importa retener alguna de las consideraciones efectuadas en el citado Informe a propósito de la peculiar situación de los terrenos de las «Vecindades». Así, se alude a la "multiplicidad de parcelas», a su "distinta localización espacial», a la "heterogeneidad» en la configuración física de aquéllas; se habla de "dispersión de la cabida», de "ausencia de alguno de los servicios urbanísticos básicos», así como de ausencia o, simplemente, de acomodación parcial «a las determinaciones urbanísticas» de aplicación, y, fundamentalmente, a la existencia de «diferentes clasificaciones y calificaciones" atribuidas por el planeamiento urbanístico vigente. Circunstancias todas ellas que aconsejan, en opinión del Técnico Municipal informante, "realizar una valoración genérica, unificando criterios y ponderando las situaciones jurídico-urbanísticas de los predios más dominantes".

Sobre la base de estas "consideraciones previas», el Informe (apartado II: "Consideraciones técnicas»), de conformidad con los principios plasmados en el reciente Real Decreto Legislativo 1/1992, de 26 de 
junio, por el que se aprueba el Texto Refundido sobre Régimen del Suelo y Ordenación Urbana, sienta los criterios de valoración de los terrenos considerados, dada, como antes se apuntó, la existencia de diferentes clasificaciones y calificaciones urbanísticas. Así, se indica que los terrenos clasificados como suelo no urbanizable (con independencia de su categoría) y como suelo urbanizable no programado, serán tasados con arreglo a su valor inicial (insistimos: en aplicación de los principios y criterios de la Ley del Suelo de 1992). Los terrenos clasificados como suelo urbano, lo serán de conformidad con el valor urbanístico de aquéllos (que evaluará, dice el Informe, "el conjunto de derechos o facultades adquiridos en función del grado de urbanización, cesión y equidistribución, conforme al Plan General», precisión que muestra la asunción en el indicado Informe de los principios rectores de la nueva legislación urbanística). Finalmente, y dentro del suelo urbano, el Informe fija las Tasaciones de los terrenos que tienen aquella clasificación atendiendo a las diferentes calificaciones de las parcelas (tres valoraciones para uso residencial y una valoración para uso industrial), y en función de los aprovechamientos urbanísticos conferidos por el planeamiento en vigor, de acuerdo con las tipologías características en la zona.

Atendiendo, en consecuencia, a las consideraciones expuestas, el Informe fija las correspondientes valoraciones de los terrenos de las «Vecindades", valoraciones que oscilan entre un mínimo de 1.000 pesetas/metro cuadrado (para suelo no urbanizable y urbanizable no programado) y un máximo de 4.470 pesetas/metro cuadrado (para suelo urbano, calificación urbanística de uso industrial -tanto industria urbana como industria taller-).

Estos son, pues, los datos que han de ser asumidos como presupuesto indispensable a la hora de encarar la exposición de las propuestas valorativas sobre las posibilidades de transformación evolutiva de los terrenos de las "Vecindades». Afrontaremos, por tanto, para concluir este dictamen, la descripción de las anunciadas propuestas valorativas.

\section{PROPUESTAS ACERCA DE LAS POSIBILIDADES DE TRANSFORMACIÓN EVOLUTIVA DE LOS TERRENOS DE LAS «VECINDADES»}

Según antes se anunció (epígrafe VIII), y salvada siempre la posibilidad de una eventual continuación del sistema de utilización de los terrenos de las "Vecindades» en régimen de aprovechamiento comunal (sistema adaptado, en su caso, a las innovaciones que la Junta Vecinal 
DICTAMEN ACERCA DE LA STIUACIÓN JURTIICA EN QUE SE ENCUENTRAN LOS TERRENOS DE LAS 'VECINDADES"

juzgue oportuno introducir en el referido aprovechamiento comunal), la transformación evolutiva de los citados terrenos, en línea con las cuestiones propuestas en la consulta a nosotros elevada (y de las que parece deducirse la intención de modificar radicalmente el régimen de uso y disfrute de los terrenos de las «Vecindades»), exige tener en consideración los siguientes extremos:

- Precisa se hace ante todo una cabal localización e identificación de los terrenos actualmente comprendidos en las "Vecindades». El informe del Técnico Municipal de 6 de julio de 1992, sintetizado en el epígrafe anterior, pone de manifiesto que la primera y principal labor en este ámbito estriba en tener un conocimiento lo más completo y acabado posible de los terrenos aquí implicados. A estos efectos, la Junta Vecinal debiera convocar, en Concejo abierto, una reunión de todos los posibles afectados (del pueblo de Pontejos, en realidad), a fin de, previas las informaciones oportunas, recabar cuantos datos fueran precisos para identificar debidamente (localización espacial y cabida) los terrenos que forman parte de las "Vecindades». Concluida esta primera fase, los terrenos así identificados debieran inscribirse en un Inventario o Registro administrativo de la Junta Vecinal, expresamente elaborado a tal fin.

- Efectuada la citada localización e identificación (espacial y de contenido), el siguiente momento exige la puntual y correcta valoración de cada una de las parcelas que forman parte de los terrenos de las «Vecindades». A efectos de cumplimentar la indicada valoración, ha de partirse de los criterios contenidos en el Informe del Técnico Municipal del Ayuntamiento de Marina de Cudeyo de 10 de marzo de 1992, esto es, han de tomarse en consideración cuantos elementos (clasificación y calificación urbanísticas, aprovechamiento urbanístico, tipologías características, accidentes geográficos,...) puedan contribuir a tasar más adecuadamente las parcelas que nos ocupan. En último término, la referida operación valorativa ha de conducir al establecimiento de una cantidad dineraria que identifique la tasación o valor de cada una de las parcelas o fincas de que se trate.

- Realizadas las operaciones de identificación/localización y valoración, es decisión de los vecinos del pueblo de Pontejos la redistribución de los terrenos así valorados, de conformidad con los criterios que se tengan por convenientes y adecuados. En todo caso, ha de tenerse en cuenta que la existencia de diferentes clasificaciones y calificaciones urbanísticas ( $\mathrm{y}$, consiguientemente, de distintos aprovechamientos urbanísticos) impone, en la operación redistribuidora, una situación de desigualdad inicial, que, a priori, podría corregirse mediante la 
modificación/revisión del planeamiento urbanístico municipal. No obstante, en cuanto decisión del planificador municipal (y decisión, en principio, libre), la alteración de la clasificación y calificación urbanística de los predios (ha de entenderse, como hipótesis de trabajo, en el sentido de homogeneización de los aprovechamientos urbanísticos recayentes sobre los terrenos de las "Vecindades"), sobre no incorporar sustancialmente factor corrector alguno en la antedicha operación redistribuidora, no ofrece ventaja añadida alguna de cara a la consecución del objetivo final de lograr la más equitativa adjudicación posible de los terrenos hoy integrantes de las "Vecindades" entre los vecinos del pueblo de Pontejos. En todo caso, sirvan estas breves consideraciones para ilustrar acerca de la necesidad de proceder con sumo cuidado en la ejecución de las distintas actuaciones tendentes a redistribuir/adjudicar las utilidades recayentes sobre los terrenos de las «Vecindades».

- En cualquier caso, y como requisito previo para poner en marcha el dibujado procedimiento de redistribución/adjudicación, la viabilidad de la citada operación (si, finalmente, según parece, ha de concretarse en la adjudicación/enajenación de los terrenos de las "Vecindades»), exige la previa desafectación comunal de los citados terrenos, y su conversión ulterior en bienes patrimoniales, de propios, de la Junta Vecinal. Esta alteración de la calificación jurídica de los terrenos en cuestión ha de efectuarse con sujeción a lo prescrito en el artículo 8 del Reglamento de Bienes de 1986, esto es, mediante expediente acreditativo de la oportunidad y legalidad de la alteración en cuestión (números 1 y 2 del citado artículo 8), o bien en virtud de la aprobación definitiva de un plan de ordenación urbana o de un proyecto de obras y servicios (artículo 8.4.a) del indicado Reglamento de 1986), posibilidad esta última impracticable de no procederse previamente a una nueva clasificación y calificación de los terrenos de las «Vecindades».

- Finalmente, ha de aludirse a una posibilidad (implícita, quizá, en la consulta a nosotros sometida) que, de cara al desarrollo urbano del pueblo de Pontejos, no puede descartarse. Posibilidad que pasa, naturalmente, por la conversión en suelo urbanizable programado de todos aquellos terrenos de las "Vecindades" que, en la actualidad, no cuentan con esta clasificación según el planeamiento en vigor, y cuya concreción exige naturalmente la previa modificación/revisión del citado planeamiento. Dicha posibilidad apela, obviamente, al designio de convertir en suelo urbano los terrenos que en la actualidad se hallan clasificados como no urbanizables o como urbanizables no programados, en cuanto operación previa para asentar sobre los solares resultantes del proceso de urbanización las correspondientes edificaciones. 
DICTAMEN ACERCA DE LA STTUACTÓN JURfDICA EN QUE SE ENCUENTRAN LOS TERRENOS DE LAS 'VECINDADES"

Pues bien, de optarse por esta posibilidad (que, insistimos, pasa naturalmente por la adaptación del vigente planeamiento urbanístico), la Junta Vecinal de Pontejos no se vería desposeida, de ser ésta la decisión finalmente adoptada, de la titularidad (dominical o propietaria) de los terrenos sobre los que hoy se asientan las «Vecindades», pues, en virtud de la constitución de un derecho de superficie (mediante el establecimiento de plazos suficientemente largos, noventa y nueve años, por ejemplo) podría mantener su derecho de propiedad sobre el suelo (superficie), sin perjuicio de atribuir las utilidades derivadas del planeamiento (vuelo) a los adjudicatarios pertinentes. Posibilidad, en todo caso, entregada a la libre disponibilidad de la Junta Vecinal de Pontejos.

\section{CONCLUSIONES}

UNA. Sitúese el origen de los bienes comprendidos en los terrenos de las «Vecindades» en un censo enfitéutico o en una donación (condicional o libre), en la actualidad los referidos terrenos son propiedad de la Junta Vecinal o Pedanía de Pontejos, Ayuntamiento de Marina de Cudeyo (CANTABRIA).

SEGUNDA. A los citados terrenos puede, dentro de la relatividad con que han de ser aplicadas categorías dogmáticas modernas a realidades históricas, atribuirse la calificación de bienes comunales, esto es, bienes propiedad, en concepto de dominio público, de la correspondiente entidad administrativa, y cuyo aprovechamiento corresponde al común de los vecinos.

TERCERA. El carácter de dominio público, sin perjuicio de su aprovechamiento comunal, permite a la entidad titular de los terrenos de las «Vecindades», esto es, la Junta Vecinal o Pedanía de Pontejos, su libre disponibilidad sobre el destino de aquéllos, lo que es tanto como decir la posibilidad de modificar la afectación de los mismos, ya otorgándoles una nueva afectación (mantenimiento de su condición de bienes de dominio público), ya transformando su naturaleza jurídica en bienes patrimoniales o de propios de la entidad propietaria, circunstancia que otorga a dicha entidad las más amplias posibilidades en relación con el destino último de los citados bienes.

CUARTA. De hacerse uso de la posibilidad señalada últimamente, y en función de los intereses de la población vecinal, al pueblo de Pontejos le son ofrecidas las vías ofrecidas en los epígrafes VIII y X, a cuyas consideraciones nos remitimos en este momento. 
QUINTA. Finalmente, a modo de síntesis, y a fin de dar respuesta a las siete cuestiones planteadas en el escrito de la Junta Vecinal de Pontejos de 10 de marzo de 1992, podemos afirmar:

1. Sitúese, como decíamos en la primera conclusión, el origen de la situación actual de los terrenos de las "Vecindades» ya en la constitución (en 1845, al parecer) de un censo enfitéutico en favor de cincuenta y dos vecinos del pueblo de Pontejos, ya en el otorgamiento de una donación (condicional o libre) de que aquéllos resultaron adjudicatarios, en la actualidad los citados terrenos son propiedad de la Junta Vecinal o Pedanía de Pontejos, en la medida en que el correspondiente censo enfitéutico (o donación, en su caso) fue constituido en atención a la condición, y en cuanto tales, de vecinos del pueblo de Pontejos de las personas beneficiarias. Personas agrupadas (las inicialmente adjudicatarias y las posteriores cuyos derechos traen causa del de aquéllas) en la entidad, hoy personificada, que asume la representación y defensa de sus intereses, la Junta Vecinal o Pedanía de Pontejos.

Los referidos terrenos de las "Vecindades», propiedad de la Junta Vecinal de Pontejos, tienen la condición de bienes comunales, es decir, bienes de dominio público cuyo aprovechamiento corresponde al común de los vecinos.

2. De admitirse, a efectos hipotéticos, que la situación actual de los terrenos de las "Vecindades» tuvo su origen en una donación condicionada (incorporación de una cláusula de prohibición de disponer, que por otro lado no consta), en la actualidad dicha eventual condición ha de considerarse extinta y sin efecto alguno, por lo que, en los términos descritos en el cuerpo de este dictamen, la Junta Vecinal de Pontejos, como titular dominical o propietaria de dichos terrenos, puede disponer de su destino.

3. Previa desafectación del carácter comunal de los terrenos de las "Vecindades", en virtud de expediente de alteración jurídica tramitado de conformidad con lo dispuesto en el artículo 8, números 1 y 2 , del Reglamento de Bienes de 1986, la Junta Vecinal de Pontejos puede enajenar aquéllos a sus actuales poseedores, en los términos y condiciones que fije oportunamente, de acuerdo con las reglas que rijan el funcionamiento de dicha entidad.

4. Igualmente, y con sujeción a los términos expresados en el número anterior, la Junta puede proceder a la venta de los terrenos desafectados a terceros no poseedores, y ello con independencia de la oportunidad o conveniencia de esta decisión. 
DICTAMEN ACERCA DE LA STTUACION JURIDICA EN QUE SE ENCUENTRAN LOS TERRENOS DE LAS "VECINDADES

En todo caso, tanto en éste como en el anterior supuesto, la venta habría de realizarse en subasta pública, con respeto a las condiciones establecidas en las oportunas bases, que habrán de ser debidamente aprobadas y publicadas.

5. Ningún obstáculo se alza a la posibilidad de poner fin al derecho de aprovechamiento que ostenten sus actuales poseedores sobre los terrenos de las "Vecindades» clasificados como suelo urbano. Mas por las razones expuestas en el cuerpo de este dictamen, de estimarse oportuno emprender una operación de transformación evolutiva de los terrenos de las "Vecindades», en el sentido ya expuesto, dicha operación debe tener carácter global o de conjunto, y no limitarse a determinados terrenos, con exclusión de los demás, en función de su clasificación urbanística.

6. De emprenderse la indicada operación de transformación evolutiva de los terrenos de las «Vecindades», y previa la desafectación de su carácter comunal, ha de procederse, una vez identificados y localizados debidamente dichos terrenos, a la valoración de los mismos. A estos efectos, puede partirse de los criterios valorativos consignados en el Informe del Técnico Municipal del Ayuntamiento de Marina de Cudeyo de 6 de julio de 1992. En consecuencia, pues, y una vez efectuada la indicada valoración, es factible que la eventual enajenación de los terrenos vaya precedida de una redistribución de los lotes que han de entrar en la operación de venta, según los criterios que la Junta Vecinal estime más oportunos.

7. En la medida en que algunos adjudicatarios de los lotes o suertes de las «Vecindades» no residan habitualmente en el pueblo de Pontejos, es decir, no tengan ya la condición de «vecinos» a efectos de participar en los aprovechamientos de los terrenos de las "Vecindades», la Junta, de conformidad con las normas por que se rija la sucesión de derechos en materia de aprovechamiento, puede constatar la pérdida de la condición de "vecinos» de las personas que se hallen en la situación de referencia y, en consecuencia, proceder a una nueva adjudicación de los aprovechamientos afectados.

Esta es nuestra opinión, que, según los modos al uso, ofrecemos a cualquiera otra opinión mejor fundada.

En Santander, a quince de enero de mil novecientos noventa y tres. 


\section{Sección Jurisprudencia}

REALA-1994, núm. 262. ROJO AJURIA, LUIS. DICTAMEN ACERCA DE LA SITUACION JURIDIC... 
